\title{
Board 75: Establishing a tech tool library with instructional resources at an academic institution
}

\section{Ms. Jean L Bossart P.E., University of Florida}

Jean Bossart is an Associate Engineering Librarian at the University of Florida (UF). She assists students with research, data support, and citation management. She investigates and integrates creative technologies, such as 3D printing into the STEM discipline library services. She has a BS in chemical engineering and MS in environmental engineering from UF, over 20 years of experience in industry and consulting, and is a licensed professional engineer in Florida.

\section{Mr. Samuel R Putnam, University of Florida}

Samuel R. Putnam, MLS, is an Engineering Librarian at the University of Florida. His research interests include engineering education, library instruction, technology in libraries, and information-seeking behavior in STEM.

Dr. Sara Gonzalez, University of Florida 


\title{
Establishing a tech tool library with instructional resources at an academic institution
}

\author{
Jean L. Bossart, Samuel R. Putnam, and Sara R, Gonzalez \\ (George A. Smathers Libraries, University of Florida)
}

\begin{abstract}
The Marston Science Library (MSL) at the University of Florida (UF) has compiled a diverse tool library equipped with tech tools and hand tools for check-out to any UF student and use at either the library or outside locations. The objective of this collection is to foster a sense of self sufficiency and sustainability among its primary users, science and engineering students. The intent is to cultivate an active learning environment and a new community of practice within the library through access to tools. As a trial of this new service, MSL made the following tools available for a 1-week check-out: computer repair kits, multimeters, precision screwdriver sets, soldering kits, digital calipers, laser levels, Dremel rotary tool kits, hand drills and bits, and homeowner tool kits. The tools are housed in rolling tools carts and are cataloged for check-out at the library service desk. Promotion for the new tool library included in-library displays, featuring on the library's homepage, printed book marks, and articles in the university newspaper. LibGuides were developed to provide instructions, safety protocols, and links to how-to videos and other instructional online resources and hands-on demonstrations were offered throughout the semester. A preliminary assessment of tool check-outs was conducted, the results of which identified the strengths of the tool-library forum, as well as opportunities for improvement. This paper accompanies a poster presented at the 2019 American Society for Engineering Education conference in Tampa, Florida and provides a discussion of the onesemester trial of the tool library at UF.
\end{abstract}

\section{Background/Literature Review}

Tool libraries work just like regular libraries but instead of loaning books to patrons, they loan tools. Tool libraries have existed in the U.S. for over 50 years ${ }^{1}$, with the first tool lending library founded in Columbus, Ohio in 1976. ${ }^{2}$ One of the oldest and largest tool libraries is in Berkeley, California at the public library, which started in 1979 and has over 3,500 tools available for check-out. ${ }^{3}$ Some tool libraries missions are to rebuild communities struck by natural disasters. Other tool libraries were established to support community endeavors such as neighborhood redevelopment and community gardens. ${ }^{4}$ Research has shown that there is an interest in a "Library of Things" and that patrons want access to items and workshops for their use. ${ }^{5}$

As a large public university, UF has an enrollment of around 55,000 students, of which some 10,000 are associated with the 9 departments, 15 degree programs, and 20 centers and institutes within the Herbert Wertheim College of Engineering. About two-thirds of the engineering students are undergraduates and all are required to have a laptop computer. ${ }^{6}$

Students' devices, whether laptops, smartphones, wearables, or tablets, experience a significant amount of wear-and-tear and require maintenance and repair. Students often ask the MSL staff about the availability of tools that students may use to repair personal technology devices, and to create objects for class, home, or research projects. To meet this need, MSL used endowment 
funds to purchase a diverse array of tools. These tools are available for student use at the library or to check out for later use at another location. MSL dedicated a specific space to house the tool library by purchasing rolling tool carts.

Helping students build confidence in their abilities is a way library programs can support engineering students. When students start an engineering internship or professional job, their employer often assumes the student has a basic knowledge of tools, such as using a drill or socket set. For students who have never been exposed to tools either at home or in class, a university tool library program can help enhance their skill set by providing access to tools and sponsoring group-learning tool-use workshops within a Makerspace venue.

Literature supports the hypothesis that tool access cultivates an active learning environment. Research has shown that university students who worked in small groups to present their ideas and rectify their designs were more successful at prototype development. ${ }^{7}$ University design courses provide access to tools and training for their students to promote making. Examples of events include design lectures, "Meet the Makers Expert Sessions", and student design presentations, all intended to increase skills and promote product design awareness. ${ }^{8}$ In a study by Galaleldin et al (2017) at the University of Ottawa on the impacts of Makerspaces on engineering education, $90 \%$ of the students in the study said that exposure to tools in Makerspaces increased their confidence level and 75\% said that accessibility to equipment and tools helped them with their design projects. ${ }^{9}$

Tool libraries are common in community public libraries ${ }^{10}$ but have only recently been made part of academic libraries. Many academic libraries loan technology to students but few have hand and power tools to build and repair for check-out. Table 1 provides a list of top ranked engineering schools with tool libraries. Only six universities on the U.S. News \& World Report's list of Best Engineering Schools had tool libraries. ${ }^{11}$ Many science and engineering students are missing the opportunity to handle tools and learn the proper use of tools.

Table 1. List of known university tool libraries.

\begin{tabular}{|c|c|c|}
\hline College/University & Location & Website \\
\hline Massachusetts Institute of Technology & Boston, MA & $\begin{array}{l}\text { http://news.mit.edu/2017/mit-libraries- } \\
\text { and-mit-makerworkshop-launch- } \\
\text { equipment-to-go-0309 }\end{array}$ \\
\hline $\begin{array}{l}\text { University of Florida Marston Science } \\
\text { Library }\end{array}$ & Gainesville, FL & https://guides.uflib.ufl.edu/toollibrary \\
\hline $\begin{array}{l}\text { University of Idaho Integrated Design } \\
\text { Lab Tool Loan Library }\end{array}$ & Boise, ID & $\begin{array}{l}\text { http://www.idlboise.com/content/tool- } \\
\text { loan-library-free-resource-idaho-power- } \\
\text { company-customers }\end{array}$ \\
\hline $\begin{array}{l}\text { University of Iowa Lichtenberger } \\
\text { Engineering Library }\end{array}$ & Iowa City, IA & $\underline{\text { http://www.lib.uiowa.edu/eng/tool- }}$ \\
\hline $\begin{array}{l}\text { University of Washington CoMotion } \\
\text { MakerSpace and Tool Lending Library }\end{array}$ & Seattle, WA & $\begin{array}{l}\text { https://comotion.uw.edu/what-we- } \\
\text { do/makerspace/tool-lending-library/ }\end{array}$ \\
\hline
\end{tabular}




\begin{tabular}{|l|l|l|}
\hline $\begin{array}{l}\text { University of Wisconsin-Madison } \\
\text { Makerspace }\end{array}$ & Madison, WI & https://making.engr.wisc.edu/search-beta/ \\
\hline
\end{tabular}

\section{Method}

A trial was conducted during the Fall 2018 semester at UF's MSL to evaluate the demand for tools. Any UF undergrad or grad student, regardless of major or department could check out the tools. The following is a partial list of the tools that were purchased and were available for 1week check-out to students during the Fall 2018 semester:

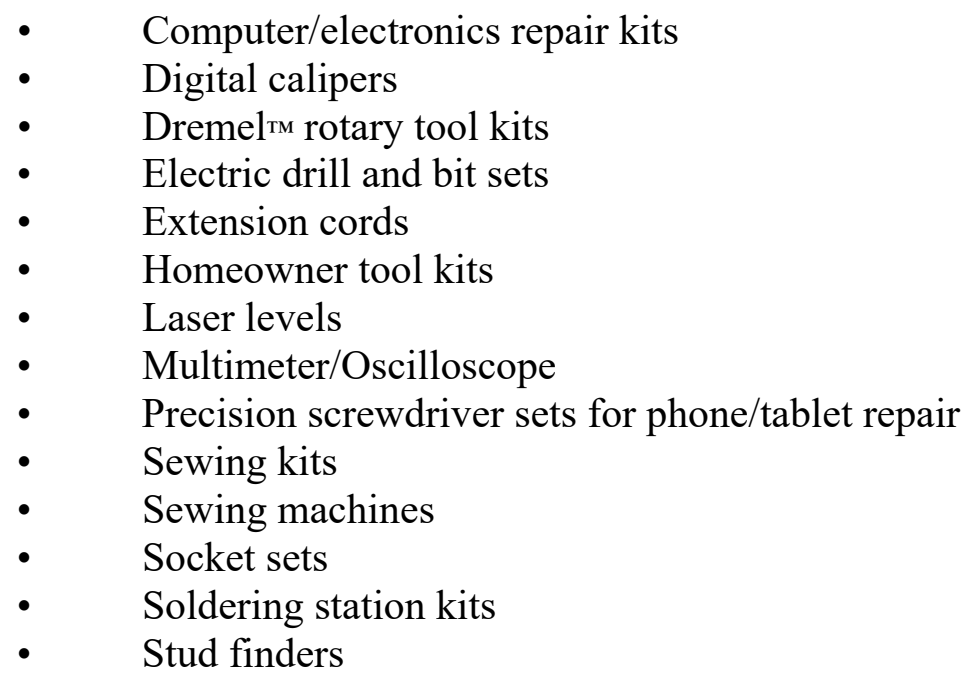

The tools were primarily tech tools but also included tools that students had requested to borrow from our 3D printing lab. These tools could be used for repairing technology or small construction projects, such as building a bookcase. Sewing machines and sewing kits were also included. Other tools made available to students for in-library use included a button maker, embroidery sewing machine, and a desktop cutting machine for vinyl, paper, and other light material. Because they have been available for check-out at MSL for over three years, Arduinos were not specifically included in the tool library trial. However, students could check-out Arduino kits with any of the tools available, if they chose to do so. There was no limit placed on the number of tools a student could check-out at the same time.

Promotion of the tool library during the Fall 2018 semester included the following:

- Displaying select tools available for check-out at the library's circulation desk

- Article in the university newspaper about the new tool library

- Inclusion in the rotating images featured on the library's homepage

- Tabling at student events and displaying some of the tools available for check-out

- Making bookmarks advertising the tool library and distributing them at library events

\section{Results}

Statistics were collected for one semester (an approximate four-month trial period) on the number of check-outs for each tool. Table 2 shows the most popular tools, the total number of 
loans, and the average number of loans per item over the four-month trial period from September 2018 through December 2018.

Table 2. Summary of circulating tool loans for a four-month trial period.

\begin{tabular}{|l|c|c|c|}
\hline Tool & $\begin{array}{c}\text { Total Number of } \\
\text { Loans }\end{array}$ & $\begin{array}{c}\text { Number of Items } \\
\text { Available for } \\
\text { Check-out }\end{array}$ & $\begin{array}{c}\text { Average } \\
\text { Number of } \\
\text { Loans per tool }\end{array}$ \\
\hline Homeowners tool kit & 25 & 7 & 4 \\
\hline Precision screwdriver set & 15 & 3 & 5 \\
\hline Digital calipers & 14 & 3 & 5 \\
\hline Computer/electronics repair kit & 12 & 5 & 2 \\
\hline Sewing machine & 11 & 2 & 6 \\
\hline Electric drill and bit set & 11 & 3 & 4 \\
\hline Sewing kit & 10 & 5 & 2 \\
\hline Soldering station kits & 9 & 3 & 3 \\
\hline Dremel rotary tool kit & 9 & 5 & 2 \\
\hline Extension cord & 8 & 3 & 3 \\
\hline Stud finder & 4 & 1 & 4 \\
\hline Socket set & 3 & 2 & 2 \\
\hline Laser level & 2 & 2 & 1 \\
\hline Multimeter/Oscilloscope & 1 & 1 & 1 \\
\hline & $\mathbf{1 3 4}$ & $\mathbf{4 5}$ & $\mathbf{3}$ \\
\hline
\end{tabular}

With 25 check-outs, the homeowner tool kit, which is a basic tool kit with a hammer, screwdrivers, pliers, tape measure, and level, was the most in demand item. The library circulates seven of these kits. Other popular tools included the precision screwdriver set, digital caliper, electric drill, and stud finder. The library circulates two sewing machines and these were also very popular with students, who often wanted to renew their loan, necessitating the establishment of a waiting list. A third sewing machine is available, but is for in-library use only and does not circulate.

Because Fall 2018 was the first semester when the tools were available for student check-out, the library focused on the logistics of checking out tools; no information was collected on the student demographics or use of the tools. Verbal feedback from students was received and was positive, with students expressing gratitude to the library for offering this "amazing" service. A user survey or other form of data collection needs to be established to assess the impact of the tool library.

Instructional resources were provided on the MSL LibGuide. ${ }^{12}$ These resources included YouTube videos on tool use and safety. Links to additional resources including projects were also included on the LibGuide.

\section{Conclusions}

With 134 check-outs during the first semester that the tool library was available to students, the tool library was considered a success. However, additional information will need to be collected 
to assess the impact of the tool library, such as who is checking out the tools and what are they using the tools for. The library will continue to monitor the number of check-outs per item and will add additional tools based on the student demand. Since libraries are central to all students, academic librarians are in a unique position to provide the tools that students need, especially engineering students. Libraries can help encourage a culture of "repair rather than replace".

\section{References}

1. Northrop, A. 2015. Does your community have a tool library?. Michigan State University Extension. Accessed January 23, 2019.

https://www.canr.msu.edu/news/does_your_community_have_a tool_library

2. Wang, F., Wang, W., Wilson, S., \& Ahmed, N. 2016. The state of library makerspaces. International Journal of Librarianship, 1(1),2-16. https://doi.org/10.23974/ijol.2016.vol1.1.12

3. Berkeley Public Library. 2014. Tool Lending Library - a brief history. Accessed January 23, 2019. https://www.berkeleypubliclibrary.org/locations/tool-lending-library/tool-lending-librarybrief-history

4. Tabor, N. 2013. Evaluating the success of tool-lending libraries and their contributions to community sustainability. Undergraduate Student Thesis University of Nebraska - Lincoln.

5. Ameli, N. 2017. Libraries of Things as a new form of sharing. Pushing the Sharing Economy. The Design Journal. 20:sup1, S3294-S3304, doi:10.1080/14606925.2017.1352833. https://doi.org/10.1080/14606925.2017.1352833

6. University of Florida Herbert Wertheim College of Engineering, Undergraduate Student Affairs. Computer requirements. Accessed February 3, 2019.

https://www.eng.ufl.edu/students/resources/computer-requirements/

7. Niiranen, S. and T. Rissanen. 2017. Learning by Doing and Creating Things with Hands: Supporting Students in Craft and Technology Education. In PATT-34 Proceedings: Fostering the Creativity of Youth Around the Globe. International Technology and Engineering Educators Association (ITEEA). Retrieved from https://www.iteea.org/File.aspx?id=115739\&v=21dfd7a

8. Wilczynski, V. 2015. Academic maker spaces and engineering design. In American Society for Engineering Education, vol. 26, p1.

9. Galaleldin, M., Bouchard, F., Anis, H. and Lague, C. 2016. The impact of makerspaces on engineering education. Proceedings of the Canadian Engineering Education Association (CEEA).

10. Local Tools. Start sharing: The easy way to manage a lending library. Accessed January 24, 2019. http://localtools.org/ 
11. U.S. News \& World Report. 2018. Best engineering schools. Accessed January 24, 2019. https://www.usnews.com/best-graduate-schools/top-engineering-schools/engrankings? mode=table)

12. University of Florida, George A Smathers Libraries. Technology @ Marston Science Library: Tool Library. Accessed January 24, 2019. http://guides.uflib.ufl.edu/msltech 